\title{
Mapeamento do termo "conhecimento", segundo relatórios de gestão, no período de 2013 a 2018, na administração municipal de Curitiba
}

\section{Mapping of the term "knowledge", according to management reports, from 2013 to 2018, in the municipal administration of Curitiba}

\author{
Andrea de F. Pfutze Cubas ${ }^{1}$ \\ 1 Prefeitura Municipal de Curitiba
}

Autor para correspondência/Mail to: Andrea de F.Pfutze Cubas, acubas@smu.curitiba.pr.gov.br

\begin{abstract}
Resumo
Introdução: o Serviço Público vem sendo cobrado a apresentar resultados diretamente ligados à prestação de serviço à sociedade, de forma que este atinja seus resultados com eficiência e efetividade.

Objetivos: este estudo tem como objetivo analisar como o tema conhecimento vem sendo empregado, e de que forma está registrado nos Relatórios de Gestão da Prefeitura Municipal de Curitiba. Este trabalho apresenta a análise e o panorama do tema conhecimento na Prefeitura Municipal de Curitiba, nos anos de 2013 a 2018.

Metodologia: sendo que para esta análise se concretizasse foi necessário, pesquisa documental nos Relatórios de Gestão, disponíveis no Portal da Transparência da Prefeitura de Curitiba, para o levantamento e quantificação do termo conhecimento, foi utilizada a análise de conteúdo de Bardin, com leitura flutuante e categorização dos dados, o que possibilitou a análise dos resultados que foi baseada a partir do conceito de gestão do conhecimento, conversão do conhecimento e ciclo SECl, de Nonaka e Takeuchi.

Resultados: o resultado obtido demonstra que as ações da Prefeitura Municipal de Curitiba, com relação ao conhecimento, expressaram uma frequência voltada ao conhecimento dedicado ao público externo em equilíbrio com o conhecimento dedicado ao público interno. Conclusão: a conversão do conhecimento para o público interno, tem o intuito de desenvolvimento de ferramentas e aprimoramento dos servidores para simplificar e proporcionar melhor desenvolvimento de tarefas internas e, por consequência, prestar adequado atendimento à população, o que demonstra o interesse no investimento no capital intelectual da prefeitura.
\end{abstract}

Palavras-chave: Conhecimento; Gestão do Conhecimento; Conversão do conhecimento.

\begin{abstract}
Introduction: the Public Service has been charged with presenting results directly linked to the provision of service to society so that it achieves its results with efficiency and effectiveness.

Objectives: this article aims to analyze how knowledge is being used and how it is registered in the Management Reports of the City hall of Curitiba. This paper presents the analysis and the scenery of the subject knowledge in the City Hall of Curitiba from 2013 to 2018.

Method: as for this analysis, it was necessary documentary research in the Management Reports, available at the Transparency Portal of the City Hall of Curitiba, for the survey and quantification of the knowledge term. We used the content analysis of Bardin, with floating reading and categorization of the data, which made possible the analysis of results that were based on the concept of knowledge management, knowledge conversion and SECI, Nonaka and Takeuchi.

Results: the result obtained demonstrates that the City hall of Curitiba's actions, related to knowledge, expressed a frequency focused on the knowledge dedicated to the external public in balance with the knowledge dedicated to the internal public.

Conclusions: the conversion of knowledge to the internal public, is aimed at developing tools and enhancing the servers to simplify and provide better development of internal tasks and, consequently, to provide adequate service to the population, which demonstrates the interest in investing in the intellectual capital of the prefecture.
\end{abstract}

Keywords: Knowledge; Knowledge management; Knowledge conversion.

\section{INTRODUÇÃO}

O Serviço Público vem sendo cobrado cada vez mais a apresentar resultados, com celeridade, qualidade e principalmente transparência, haja vista os últimos acontecimentos no cenário político, diretamente ligado à prestação de serviço à sociedade, de forma que este atinja resultados com eficiência, ou seja, que tenha a capacidade de produzir cada vez mais, com o mínimo de recursos, isto associado à eficácia, sempre atento aos prazos ou metas estipuladas, e a efetividade dos serviços prestados.

Tem-se ainda a exigência de atender a tudo isso enfrentando a crescente escassez de recursos financeiros, o que culmina na escassez de recursos humanos, assim demandando criatividade com relação a gestão estratégica de pessoas.

Analisar a gestão do conhecimento é de suma importância, pois se trata de um tema que a muito deixou de ser apenas uma experiência das organizações privadas, tornando-se um alicerce para as organizações públicas, em muito colaborando para implementação de ações, cultura da organização e, principalmente, contribuindo 
para o processo do planejamento estratégico e da capacitação dos servidores públicos, no que se refere ao capital intelectual.

E ao analisar, nos últimos 6 anos, o que vem sendo publicado nas prestações de contas da Prefeitura de Curitiba (PMC), observam-se alguns indicativos de como podem ser ampliadas as ações de gestão do conhecimento, transformando o potencial do conhecimento implícito em explícito e também como provocar a reflexão da necessidade de se criar ferramentas ou maneiras de incentivo e captação do conhecimento tácito de servidores, que podem contribuir significativamente com o conhecimento adquirido por meio de ações e programas, investidos pela PMC.

Assim, o objetivo geral deste estudo é analisar como se dá o registro do conhecimento nos relatórios de gestão da Prefeitura Municipal de Curitiba, no período de 2013 a 2018. Para o alcance do objetivo geral, tem-se os seguintes objetivos específicos: apresentar o referencial teórico referente a gestão conhecimento; mapear os dados que tratam do conhecimento nos relatórios de gestão de 2013 a 2018; analisar os dados referentes ao conhecimento nos relatórios de gestão de 2013 a 2018.

No que se refere à gestão de conhecimento e planejamento, com vistas a retenção e disseminação de conhecimentos, Lara (2004) destaca que "a gestão competente do conhecimento é um fator importante que determina a capacidade de sociedades, organizações e seres humanos lidarem com um ambiente dinâmico e de crescente complexidade". Lara (2004, apud Silva, 2018).

Programas e ações de capacitações, são fatores de promoção e disseminação de conhecimento que demonstram o interesse da organização na constituição e consolidação da cultura organizacional. Portanto merecem especial atenção.

Quando se trata da administração pública, não é diferente; o conhecimento também é base estruturante, assim como redes de conhecimento são importantes e necessárias para a gestão e manutenção dos serviços prestados aos cidadãos e às organizações.

Outro destaque que merece especial atenção na estratégia organizacional, são os programas e ações de capacitação, pois são um dos meios de promoção e disseminação de conhecimento, e demonstra o interesse da organização na constituição e consolidação da cultura organizacional.

Para aprofundar o assunto relacionado à gestão do conhecimento é necessário esclarecer alguns tópicos que mesclam o conceito de Gestão do conhecimento. Desta forma, é importante entender os conceitos e as diferenças entre dados, informação, conhecimento, conhecimento tácito e conhecimento explícito e como cada um destes se configura.

Pode-se dizer que dado é algo que sugere, ou ainda que está no seu estado bruto

os dados são elementos brutos, sem significado, desvinculados da realidade. São, segundo Davenport (1998, p. 19), "observações sobre o estado do mundo". São símbolos e imagens que não dissipam nossas incertezas. Eles constituem a matéria-prima da informação. Dados sem qualidade levam a informações e decisões da mesma natureza. Davenport (1998, p. 19 apud Angeloni, 2003, p. 18).

No que diz respeito aos dados, Santos (2001, apud Corrente), considera que os dados em si, não são dotados de relevância, mas são a soma para constituição da informação, ou "conjunto de fatos distintos e objetivos, relativos a eventos" (Davenport \& Prusak apud Gantus, 2012).

Segundo Kakabadse, Kakabadse e Kouzmin (2003), informação é o agrupamento de dados e conhecimentos organizados que formam o registro de alguma ocorrência ou fato ou inserido dentro de contexto, algo que informa (Kakabadse, Kakabadse e Kouzmin, 2003 apud Gonzalez e Martins, 2017).

No que concerne ao conhecimento, podemos concluir que o conhecimento é um conjunto de dados e informações, sendo "... criado apenas pelos indivíduos" (Nonaka \& Takeuchi, 2008, p. 25). Nas organizações, o conhecimento pode ocorrer no formato concebido por Simon, que o define como: "máquina de processamento da informação" ( Herbert \& Simon apud Nonaka e Takeuchi, p. 18-19, 2008).

Neste sentido, vamos nos limitar a tratar de conhecimento no âmbito da organização pública e como ela se configura na Prefeitura Municipal de Curitiba, tomando como base a análise dos Relatórios de Gestão referente aos anos de 2013 a 2018.

Para Grant (1996), a vantagem competitiva é alcançada por meio do aperfeiçoamento contínuo e da inovação do processo produtivo e do produto, e o conhecimento é o recurso organizacional que permite a organização desenvolver tais atividades de melhoria e inovação (Grant, 1996, apud Gonzalez e Martins, 2017).

Embora as organizações públicas não visem o lucro, investir no conhecimento é necessário, pois é por meio da capacitação dos servidores, que se vislumbra a melhoria e a inovação voltada aos serviços públicos, prestados à comunidade. 
A classificação do conhecimento nas dimensões explícito e tácito foi, inicialmente, proposta por Polanyi (2008). Para Oliveira,

o conhecimento explícito, ou codificado, refere-se ao conhecimento que é transmissível em linguagem formal, sistemática, enquanto o conhecimento tácito possui uma qualidade pessoal, o que o faz mais difícil de formalizar e comunicar (Oliveira, 2001, p. 133, apud Jannuzzi e Sugahara, p. 107, 2016).

O conhecimento explícito é visível, palpável, objetivo, expresso em linguagem, símbolos, números, sinais, livros, bancos de dados. Cardoso, Leonor, Pedro, citam que "ao falar de conhecimento explícito, Polanyi (1958) refere-se ao conhecimento que é expresso articuladamente, àquele que geralmente se tem em mente quando se utiliza a palavra "conhecimento" (Polanyi, 1958, apud Cardoso e Cardoso, p. 46, 2007).

Já o conhecimento tácito é impalpável, pessoal, individual, subjetivo (ligado a experiência, a vivência, memória, habilidades, sentimentos, é complicado para se expressar, que foi processado por sua experiência profissional, adquirido pelo arcabouço de conhecimento, sua expertise, portanto pertence ao indivíduo. Cardoso, Leonor Pedro, pág.44, entendem que o "conhecimento tácito é algo que se sabe, possivelmente mesmo, na ausência da capacidade para se explicar", ou seja, é um conhecimento difícil de se mensurar.

Comparando os dois tipos de conhecimento, Oliveira Junior, destaca que "o conhecimento explícito, ou codificado, refere-se ao conhecimento que é transmissível em linguagem formal, sistemática, enquanto o conhecimento tácito possui uma Gestão do conhecimento" (Oliveira Jr., 2001, p. 133).

Segundo Takeuchi e Nonaka (2008, p. 23), o conhecimento explícito e tácito sofre quatro conversões, conforme ilustrado na figura 1, são elas:

a) Socialização: de tácito para tácito;

b) Externalização: de tácito para explícito;

c) Combinação: de explícito para explícito, e;

d) Internalização: de explícito para tácito.

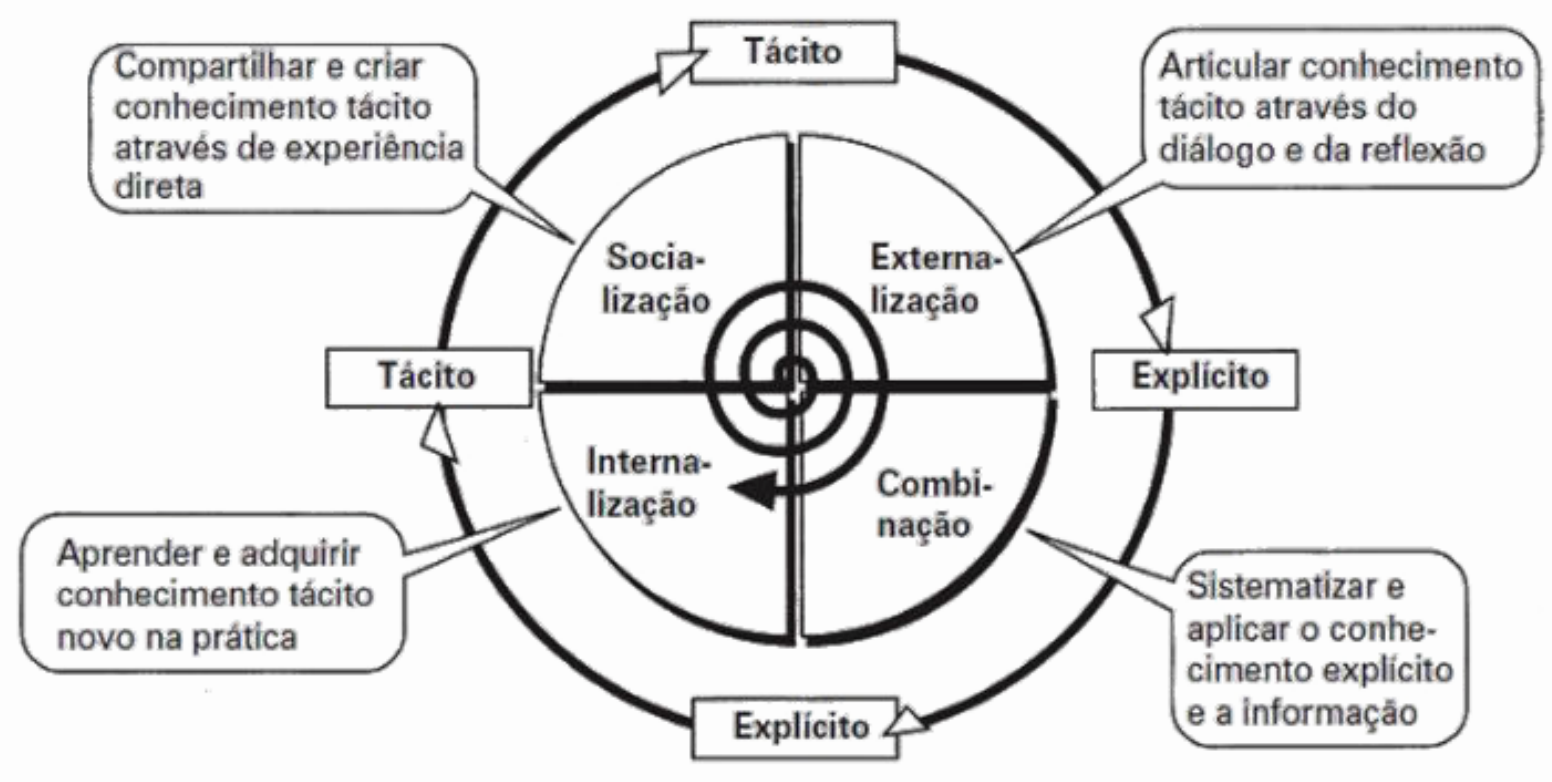

Figura 1. Ciclo SECl de conversão do conhecimento Fonte: Nonaka e Takeuchi (2008, p. 24)

Na literatura especializada, é comum encontrar referências aos 4 modos de conversão, ou ciclo de conversão, na forma da sigla SECI: Socialização, externalização, combinação e internalização. É também "conhecido, como: modelo SECI, espiral SECI, ou processo SECI" (Nonaka \& Takeuchi, 2008, p. 23), tendo em vista que facilita a indicação do assunto a ser tratado, pois simplifica o entendimento, uma vez que mencionado se sabe que se trata do movimento completo de conversão do conhecimento.

Segundo Nonaka e Takeuchi (2008, p. 24), "uma organização cria e utiliza conhecimento convertendo o conhecimento tácito em conhecimento explícito, e vice e versa." 


\begin{tabular}{lrrrr}
\hline Ano & $\begin{array}{r}\text { Total de páginas } \\
\text { dos Relatórios de } \\
\text { Gestão }\end{array}$ & $\begin{array}{r}\text { Páginas com } \\
\text { palavra } \\
\text { conhecimento }\end{array}$ & $\begin{array}{r}\text { Total de palavras } \\
\text { no texto com } \\
\text { conhecimento }\end{array}$ & $\begin{array}{r}\text { Total de palavras } \\
\text { conhecimento }\end{array}$ \\
\hline 2013 & 700 & 60 & 2539 & 66 \\
2014 & 575 & 35 & 2385 & 43 \\
2015 & 547 & 46 & 3849 & 51 \\
2016 & 602 & 54 & 4528 & 65 \\
2017 & 459 & 47 & 2160 & 53 \\
2018 & 531 & 55 & 2181 & 72 \\
\hline TOTAL & 3.414 & 297 & 17.642 & 350 \\
\hline MÉDIA/ANO & 569 & 49,5 & 2940 & 58,3 \\
\hline
\end{tabular}

Tabela 1. Palavra conhecimento no Relatório de Gestão da Prefeitura Municipal de Curitiba $(2013,2014,2015,2016,2017,2018)$ Fonte: Elaborado pela autora (2018).

\section{METODOLOGIA}

O estudo foi realizado por meio de pesquisa qualitativa, exploratória e documental. A pesquisa documental, segundo Fonseca (2002, p. 32), "recorre a fontes mais diversificadas e dispersas, sem tratamento analítico, tais como: tabelas estatísticas, jornais, revistas, relatórios, documentos oficiais, cartas, filmes, fotografias, pinturas, tapeçarias, relatórios de empresas, vídeos de programas de televisão, etc".

Assim, em função da fonte dos dados, entende-se que a pesquisa realizada trata de pesquisa documental, tendo em vista que nos utilizamos de dados coletados dos Relatórios de Gestão da Prefeitura Municipal de Curitiba, dos períodos de 2013 a 2018.

Por ser o documento oficial de prestação de contas anual das ações realizadas pela administração municipal, sendo amplamente divulgado e disponível no portal da transparência do município, o Relatório de Gestão da Prefeitura de Curitiba foi definido como fonte de análise para este estudo. Este documento é utilizado para os estudos acadêmicos, e também como fonte de consulta interna pelos gestores da Prefeitura.

Desta forma, foi escolhido para este estudo os anos mais recentes, e incluindo ações de duas gestões do governo municipal: uma completa de 2013 - 2016 e a atual gestão que tem 2 anos, iniciada em 2017, totalizando as ações dos últimos 6 anos.

Para a quantificação do termo "conhecimento" nos Relatórios de Gestão de 2013 a 2018, foi utilizada a análise de conteúdo de Bardin (1994) com leitura flutuante e categorização dos dados. Segundo Bardin (1994), há três fases sequenciais para a análise de conteúdo, a saber: "1. a pré-análise; 2) a exploração do material; 3) o tratamento dos resultados, a inferência e a interpretação."(Bardin, 1994, p. 95).

Na pré-análise, foi escolhido o relatório de gestão e foi realizado o levantamento da frequência com que surgia a palavra "conhecimento".

Na exploração do material, foi feita uma análise dos dados levantados, sendo que foram tratados os resultados levantados, com a frequência simples das ocorrências das categorias trabalhadas em três etapas.

Primeiramente, foi levantado os arquivos dos relatórios de gestão, de 2013 a 2018, disponíveis no Portal da Transparência da Prefeitura de Curitiba. Em seguida, por meio da ferramenta de pesquisa do Adobe Acrobat, $($ ctrl + f), foi selecionado e extraída a parte dos textos e frases que apresentavam a palavra conhecimento. Passou-se então para o terceiro passo, que foi a elaboração de planilha com o texto coletado e após a leitura flutuante e releitura do conteúdo coletado, foi realizada a análise do contexto em que a palavra conhecimento estava inserida. Cabe informar que análise foi baseada na espiral do conhecimento, adaptada de Nonaka e Takeuchi (2008).

\section{CONHECIMENTO NO RELATÓRIO DE GESTÃO}

Baseando-se na tabela de conversão do conhecimento adaptada de Nonaka e Takeuchi (2008), apresentada na Figura 1, e nos registros dos Relatórios de Gestão da Prefeitura Municipal de Curitiba, disponíveis no Portal da Transparência, foi realizado um levantamento das ocorrências no tocante ao conhecimento.

Os relatórios de gestão do período de 2013 a 2018, são documentos que registram as ações de todos os órgãos e entidades da Prefeitura de Curitiba, com as seguintes características: em média com 569 páginas por ano, e com 297 páginas no total dos 6 anos; com a palavra "conhecimento" aparecendo 350 vezes, sendo que somente 4 vezes esta não estava no contexto da gestão do conhecimento, e sim apenas manifestavam o ato de dar ciência.

Para a quantificação do termo "conhecimento" nos Relatórios de Gestão de 2013 a 2018, foi utilizada a frequência em que o termo apareceu. Todo o conteúdo extraído dos relatórios de gestão 2013 a 2018, foram transferidos 


\begin{tabular}{lrrrr}
\hline Ano & Prequência & Público externo & Público interno \\
& 29 & $\%$ & Frequência & $\%$ \\
2013 & 20 & $8 \%$ & 37 & $11 \%$ \\
2014 & 23 & $6 \%$ & 19 & $6 \%$ \\
2015 & 34 & $10 \%$ & 37 & $8 \%$ \\
2016 & 38 & $11 \%$ & 16 & $5 \%$ \\
2017 & 51 & $15 \%$ & 22 & $6 \%$ \\
2018 & 195 & $56 \%$ & 151 & $44 \%$ \\
\hline TOTAL GERAL & & &
\end{tabular}

Tabela 2. Frequência do termo conhecimento para público interno e externo da Administração Municipal de Curitiba - 2013-2018 da Prefeitura Municipal de Curitiba

Fonte: Elaborado pela autora (2018).

\begin{tabular}{ccrrrrr}
\hline Tipo de conhecimento & \multicolumn{1}{c}{ Explícito } & \multicolumn{3}{c}{ Tácito } \\
\hline Ano & Externo & Interno & Total & Externo & Interno & Total \\
\hline 2013 & 16 & 20 & 36 & 13 & 17 & 30 \\
2014 & 18 & 15 & 33 & 2 & 4 & 6 \\
2015 & 14 & 17 & 31 & 9 & 11 & 20 \\
2016 & 29 & 11 & 40 & 5 & 18 & 23 \\
2017 & 33 & 7 & 40 & 5 & 9 & 14 \\
2018 & 39 & 8 & 47 & 12 & 14 & 26 \\
\hline TOTAL & 149 & 78 & 227 & 46 & 73 & 119 \\
\hline
\end{tabular}

Tabela 3. Frequência do conhecimento interno e externo nos Relatórios de Gestão 2013-2018 da Prefeitura Municipal de Curitiba Fonte: Elaborado pela autora (2018).

para planilhas, que deram origem às tabelas que serão exibidas e analisadas a seguir.

Na pesquisa realizada nas 3.414 páginas, foram extraídas em média 58,3 palavras em referência ao "conhecimento" nos 6 anos de relatório, a frequência da palavra conhecimento foi a demonstrada na tabela 2.

Quanto a evolução do termo conhecimento durante os 6 anos analisados, podemos afirmar que dos 346 registros de conversão do conhecimento, $66 \%$ de registros voltado ao conhecimento externos, e 33

Observa-se ainda, que a tabela 2 apresenta movimento de ascendência expressiva referente à palavra conhecimento, voltado ao externo, movimento este que inicia de 2016, com considerável ascendência em 2018.

Analisando o termo conhecimento nas ações realizadas para o público interno da Administração Municipal de Curitiba e para o público externo, observa-se na tabela 2 um movimento de ascendência expressiva referente à palavra conhecimento, um voltado às ações direcionadas ao público externo, movimento este que inicia de 2016, com considerável ascendência em 2018. Já, no que concerne ao público interno, que compreende aos servidores da prefeitura, apresentou tímido movimento de ascendência, mas com características ainda de expressiva de retomada do crescimento.

Nas dimensões de conhecimento explícito e tácito, descreve-se a distribuição da frequência em que o registro do termo conhecimento foi encontrado no relatório de gestão referente ao conhecimento implícito e explícito, tanto para o público interno da Prefeitura de Curitiba, como para o público externo da administração municipal que é o cidadão.

Conhecimento explícito é aquele que se apresenta de maneira protocolar, organizado e planejado, fácil de expressar. Já o conhecimento tácito é aquele classificado como individual, adquirido e processado mediante a experiência própria, de complexo compartilhamento.

Quando se trata do conhecimento explícito para o público externo se percebe que nos relatórios de gestão de 2013 a 2018, este representa $42 \%$ do total de 346 registros de conversão do conhecimento geral, já demonstrada na tabela 2. No contexto do conhecimento, observa-se que o conhecimento explícito aparece nos planos de governo, capacitações internas e externas, programas e projetos de governo, ações coordenadas por secretarias, projetos, missão, relatórios das principais realizações entre outros. O conhecimento explícito para o público interno, representa $22 \%$ do total geral. Assim como conhecimento explícito para o público externo, são apontadas, ações como: relatórios de realizações, capacitações, projetos, porém em menor volume.

Observa-se que o contexto do conhecimento tácito nas ações externas, nos relatórios de gestão de 2013 a 2018, reflete em torno de 13\% das manifestações, e surgem nos planos de governos, programas e capacitações.

Sendo que o contexto do conhecimento tácito para as ações internas representa $20 \%$, se mostra com pequena variação com o contexto do conhecimento explícito/interno. Este emergiu nas ações de articulações de conhecimento, fomento, ampliação, gestão, disseminação, socialização e articulação do conhecimento. 
Registros externos ou explícitos se referem àquele que é externalizado, que vem do conhecimento tácito de um indivíduo ou grupo de uma organização, e neste caso explicitado, compartilhado ou socializado pela Prefeitura Municipal de Curitiba, é o ato de dar conhecimento promovendo e articulando o conhecimento, seja por meio da forma escrita ou oral.

Dos 227 registros de conhecimento, 150 são referentes ao conhecimento explícito para o público externo. A disseminação ocorre, segundo os relatórios de gestão de 2013 a 2018, na forma de plano de governo, programas desenvolvidos pelos órgãos e entidades municipais, por meio de mobilizações, ações em parceria com outros municípios, nacionais e internacionais ou outras entidades (universidades, e bancos), disseminação através de informativos, projetos e serviços e até mesmo como a explicitação da missão destes órgãos e entidades.

A promoção do conhecimento se deu através de atos como: semear conhecimento, difundir conhecimento, gestão do conhecimento, articulação de conhecimento, integração de conhecimento com a RMC, promoção de cultura, rodas de conversas, compartilhamento de conhecimento através de intercâmbio, empoderamento por meio do conhecimento e conhecimento por intermédio da transparência.

No que concerne ao conhecimento tácito ao público externo, constatou-se 120 registros, e destes 46 são tácitos.

Tácito é aquele conhecimento que foi processado agregando-se, experiência pessoal de um indivíduo à experiência ou profissional, desenvolvendo assim sua expertise, portanto é aquele conhecimento pertencente ao indivíduo e cabe somente a ele a decisão de repassar, externalizar e socializar seu arcabouço profissional.

Neste sentido, identificou-se que conhecimento tácito para o público externo, segundo os relatórios de gestão da Prefeitura Municipal de Curitiba de 2013 a 2018, se caracterizam em: rodas do conhecimento, oficinas, palestras fomentadoras de conhecimento e reflexões, ações de integração conjuntas, compartilhamento de conhecimento nacional e internacionalmente, compartilhamento de boas práticas.

Examinando as informações da tabela 3, percebe-se que com relação ao conhecimento interno/explícito num total 227, se apresentam 77 ocorrências do movimento explícito, e estes se caracterizam, em forma de avaliações de conhecimento, abertura de conhecimento de modo virtual, capacitações de servidores e gestores da PMC, articulações de conhecimento, publicação de práticas internas, cursos de aprofundamento, convênios e cooperações, ampliação de conhecimento tecnológico, proporcionar conhecimento, compartilhamento e acompanhamento de práticas, disseminação de conhecimento e promoção da transferência do conhecimento. Estas ocorrências foram promovidas, por ações propostas pelo plano de governo, capacitação, programas, projetos, análise ou balanço das realizações de projetos e programas.

Correspondente ao conhecimento interno/tácito, do total de 120 registros, houve a vigência de 74 eventos relacionados ao movimento tácito, configurado em ações internas da Prefeitura, que promoveu a ampliação do conhecimento, pesquisas, fomento ao conhecimento, busca pelo conhecimento, produção de conhecimento, compartilhamento de conhecimento, agregador de conhecimento, intercâmbio de conhecimento e disseminação de novos saberes. Estas ocorrências foram promovidas pelo programa de governo, planejamento e monitoramento, processo de avaliação, realizações e gestão através da implantação de projetos, capacitações, formação de profissionais, revistas eletrônicas, seminários e ações de capacitação promovidas por comitês.

A tabela 3 demonstra a evolução no tempo do conhecimento explícito/externo, no período, pode-se observar que o conhecimento explícito/externo, se manteve de certa forma constante no período de 2013 a 2015, apresentando um movimento ascendente de 2016 a 2018.

Quanto a atividade do movimento de conhecimento tácito do público externo, verificamos uma queda considerável a partir do ano de 2014, tendo uma pequena expressão de retomada até o ano de 2017, e uma considerável recuperação em 2018. Já para a evolução do movimento de conhecimento explícito/interno, percebemos uma desaceleração a partir de 2017, com uma pequeníssima variação com crescimento em 2018. Quanto ao conhecimento tácito/interno se configura de forma homogênea no período dos 6 anos, dando pistas de movimento ascendente a partir de 2018.

Analisando o ciclo de conhecimento, com os 4 movimentos de conversão do conhecimento SECI, socialização, externalização, combinação e internalização, tem-se que estes movimentos não necessariamente são únicos em cada ação de gestão do conhecimento, por isso aparecem uma ou mais vezes na frequência da tabela 4 .

Na tabela 4, que trata da Configuração da Espiral do Conhecimento nos Relatórios de Gestão 2013 a 2018 , da Prefeitura Municipal de Curitiba, observa-se as dimensões de conhecimento.

Analisando a tabela 4, observa-se que do total das ocorrências em torno de $30 \%$ do total de 346 registros de conversão do conhecimento geral, foram voltadas para a criação de conhecimento, pois houve o compartilhamento de conhecimento, seja pelo compromisso do plano de governo ou por ações promovidas pelas distintas secretarias da PMC, pelo meio de rodas de conversas, práticas de educação, reuniões com instituições, integração e parcerias promovendo trocas de conhecimentos.

O movimento denominado de Socialização, que nada mais é que o compartilhamento do conhecimento adquirido 


\begin{tabular}{ccrrrr}
\hline Público & & Externo & & Interno & Total \\
\hline Conversão do Conhecimento & Total & (1) $^{(1)}$ & Total & \% & $19 \%$ \\
\hline Socialização & 105 & $15 \%$ & 92 & $18 \%$ & 290 \\
Externalização & 163 & $23 \%$ & 127 & $9 \%$ & 105 \\
Combinação & 45 & $6 \%$ & 60 & $9 \%$ & 114 \\
Internalização & 54 & $8 \%$ & 60 & 9 \\
\hline
\end{tabular}

Tabela 4. Configuração da Espiral do Conhecimento nos Relatórios de Gestão 2013-2018 da Prefeitura Municipal de Curitiba Fonte: Elaborado pela autora (2018).

(1) \% em relação ao total de 346 registros do termo conhecimento

através da observação, conversão por experiência direta ou prática, com o intuito de dividir o conhecimento ou criar o conhecimento, fundamentado no que já se conhece para o público interno da prefeitura, foram analisados do total de 346 por volta de $26 \%$ como socialização e foram detalhados os relatórios de gestão de 2013 a 2018 , em forma de projeto de plano de governo, capacitações de servidores proporcionados para desenvolvimentos profissionais, por produção de conhecimento, mostras e publicações de pesquisas desenvolvidas por servidores e socializadas internamente através de revistas eletrônicas, seminários para disseminar de práticas, diálogos com servidores, visando a uniformização de serviços, nos apresentando o conhecimento já consolidado, advindo do indivíduo e externado à um grupo, seja por escrita ou diálogo que remeta a reflexão.

Já a linha de socialização de conhecimento externo, apresentados nos relatórios de gestão de 2013 a 2018 , se moldou através de programas de governo, governança participativa, surgiu também em balanço das principais realizações (prestação de contas). A palavra conhecimento manifestou-se no desenvolvimento, disseminação, produção, aprofundamento, oferta de conhecimento e rodas de conversa.

A externalização se configura na exposição de conhecimento tácito, podendo ser de um indivíduo para um grupo. $\mathrm{Na}$ análise dos relatórios de gestão, identificamos que $45.5 \%$ da externalização/externa e $34.5 \%$ externalização/interna. No que diz respeito a externalização/externa, identificamos atuações do plano de governo, autoavaliação da PMC, com relação as realizações do plano de governo, ação das instituições, como: possibilitar conhecimento, promoção de rodas do conhecimento, gestão compartilhada com outros municípios e estados, como a troca e compartilhamento de experiências, conhecimento voltado da cultura e ações conjuntas. A externalização/interna, se desenhou na ampliação do conhecimento, preparação do servidor, produção do conhecimento, cursos, socialização, viabilização de conhecimento, disseminação de novos saberes, materialização do conhecimento, entre outro.

Com relação combinação de conhecimento analisada nos relatórios de gestão 2013 a 2018, equivale àquela troca de conhecimento que se imprime através de reuniões ou por meio de redes de comunicação, e dão origem a algum tipo de documento ou instrução, seja de diretrizes e procedimentos, ou até mesmo de organização, que possibilite se empregar o que foi adquirido pelo conhecimento, podendo ser conhecimento socializado ou externalizado, fazendo ou não, a ligação com o conhecimento internalizado.

Visualiza-se que a combinação de conhecimento externo, representa $12 \%$ movimento, e este é manifestado por planos de governo, programas, redes de soluções urbanas, se configurado na realização de reuniões, rodas de conversa, visitas técnicas.

Como combinação para o público interno, identificamos que do total geral de 346 ocorrências, esta categoria representa em torno de $17 \%$ e de forma equilibrada com a combinação externa, sendo que esta, se caracteriza como ações de plano de governo, análise de resultados e principais realizações, identificamos que tais ações se apresentam por capacitações de servidores e gestores, planejamento, aprimoramento e disseminação de conhecimento e viabilização de aplicações de conhecimentos adquiridos.

Os relatórios de gestão de 2013 a 2018, apresentam a internalização de forma equilibrada representando em torno de $15,5 \%$ e 16,5\%, respectivamente em relação ao total geral de 346 ocorrências, que corresponde a execução por meio de ações de gestão, capacitações, projetos de socializações digitais, análise de resultados e parcerias. Internalização/externo, é demonstrada na tabela, pela troca de conhecimento e experiências entre os participantes. Outra forma é a de disseminação do conhecimento em torno de variados temas, realizações de capacitações, informando a população de que forma acessar seus direitos, integração de conhecimento, seja como captação ou transferência de conhecimento.

O processo de internalização para os servidores, isto é para o público interno, nos relatórios de gestão 2013 a 2018, caracterizou-se pelo de desenvolvimento de habilidades, disseminação, viabilização, visualização, aplicação, reprodução, aprimoramento, produção, do conhecimento, assim como desenvolvimento metodológico de trabalho, com o intuito de contribuir para o desenvolvimento do servidor.

Observou-se que tais ações se apresentaram em planos de governos, desenvolvimentos de programas que primavam por capacitações coordenados pelas respectivas secretarias, fundações e institutos. Entretanto verificou-se que a 
expressão do conhecimento internalizado para o público interno, foi constatada com maior incidência no ano de 2013.

\section{CONSIDERAÇÕES FINAIS}

O presente trabalho apresentou um panorama de como o tema gestão do conhecimento vem sendo registrado na Administração Municipal de Curitiba, no que tange ao compartilhamento, a captação e disseminação do conhecimento. Foram analisadas as 160 páginas, dos Relatórios de Gestão de 2013 a 2018 e os 346 registros da palavra "conhecimento", o que subsidiou o desenvolvimento do objetivo geral desta pesquisa, que foi descrever e analisar como acontece o registro do conhecimento nos relatórios de gestão, da Prefeitura Municipal de Curitiba.

Conclui-se que após a análise e mapeamento dos registros da palavra "conhecimento", que nos relatórios de gestão de 2013 a 2018, somado aos modos de conversão do conhecimento, socialização, externalização, combinação e internalização expressam a conversão do conhecimento voltado ao público externo (voltado à população) com ações que promovem a socialização de conhecimento, difusão de conhecimento, voltada ao esporte a educação, segurança, sustentabilidade urbana, acessibilidade, saúde, capacitações, interação com outras capitais, com a região metropolitana de Curitiba, outros estados, outros órgãos, produção de conhecimento com vistas à emancipação individual e conscientização coletiva, capacitações e fomento ao microempreendedorismo, rodas do conhecimento para melhoria da qualidade de vida, contribuições científicas, mostras de serviços, campanhas e até mesmo intercâmbios para captação e compartilhamento de conhecimento. Estas ações fazem parte de planos e programas de Governo, desenvolvidas pelas Secretarias Municipais, Institutos e Autarquias.

Foi constatado também que a conversão do conhecimento para o público interno, ou seja, voltado às instituições e servidores tem ações como ampliação do conhecimento, capacitações, realização de cursos com parcerias, direcionados a linhas de atuação, inovação, produção do conhecimento, aprofundamento, socialização do conhecimento, aplicação, compartilhamento, integração, captação, materialização, nivelamento, articulação e transmissão do conhecimento, todas elas com o intuito de desenvolvimento de ferramentas e aprimoramento dos servidores para simplificar e proporcionar melhor desenvolvimento de tarefas internas, e por consequência prestar adequado atendimento à população, o que demonstra o interesse no investimento no capital intelectual da prefeitura.

Baseando-se nos resultados da pesquisa da conversão do conhecimento, motivados pela frequência do surgimento da palavra conhecimento, entendemos que este estudo merece ser explorado, em trabalhos futuros, para tratar os dados colhidos, com um olhar mais aprofundado. Sugere-se utilizar a metodologia bibliométrica de Zipf. Considerando-se, que instiga o fato das ações voltadas tanto para o público interno como ao externo, poder estar expressando, o ciclo completo de Socialização, Externalização, Combinação e Internalização. É instigante e motivador testemunhar que o conceito desenvolvido por especialistas, pode sim se concretizar, ou seja, proporcionar ferramentas de análise, que possibilitem a visualização de movimentos de conversão do conhecimento e pelo fato de estar tratando de algo intangível, como o investimento do capital intelectual, que é difícil de se mensurar resultados. 


\section{REFERÊNCIAS}

Angeloni, M. T. (2003). Organizações do conhecimento: Infra-estrutura, pessoas e tecnologia. Saraiva.

Bardin, L. (1994). Análise de conteúdo. Edições 70.

Cardoso, L., \& Cardoso, P. (2007). Para uma revisão da teoria do conhecimento de michael polanyi. Revista Portuguesa de Pedagogia, 41(1), 41-54. Recuperado em 01 fev. 2019, de https://impactum-journals.uc.pt/rppedagogia/ article/view/1184/632

de Lara, C. R. D. (2004). A atual gestão do conhecimento: a importância de avaliar e identificar o capital intelectual nas organizações. Nobel.

Fonseca, J. J. S. (2002). Metodologia da pesquisa científica. Apostila.

Gantus, C. (2012). Conceitos básicos de gestão do conhecimento.

Gonzalez, R. V. D., \& Martins, M. F. (2017). Knowledge management process: a theoretical-conceptual research. Gestão E Produção, 24 (2), 41-54.

Jannuzzi, F. O. M., Celeste Sirotheau Corrêa, \& Sugahara, C. R. (2016). Gestão do conhecimento: um estudo de modelos e sua relação com a inovação nas organizações. Perspectivas em Ciência da Informação, 21(1), 97-118. Recuperado em 20 jan. 2019, de https://impactum-journals.uc.pt/ rppedagogia/article/view/1184/632 doi: 10.1590/1981$5344 / 2462$

Nonaka, I., \& Takeuchi, H. (2008). Gestão do conhecimento. Bookman. (Tradução de Ana Thorell)

Oliveira Jr., M. d. M. (2001). Competências essenciais e conhecimento na empresa. In M. T. L. Fleury \& M. d. M. O. Oliveira Jr. (Eds.), Gestão estratégica do conhecimento: integrando aprendizagem, conhecimento e competência (p. 121-156). São Paulo: Atlas.

Polanyi, M. (2008). The tacit dimension. Routledge.

Prefeitura Municipal de Curitiba. (2013). Relatório de gestão 2013. Instituto Municipal de Administração Pública. Recuperado em 05 jan. 2019, de http://imap.curitiba.pr.gov.br/wp-content/uploads/2017/ 07/relatorio_de_gestao_2013.pdf

Prefeitura Municipal de Curitiba. (2014). Relatório de gestão 2014. Instituto Municipal de Administração Pública. Recuperado em 05 jan. 2019, de http://imap.curitiba.pr.gov.br/wp-content/uploads/2017/ 07/relatorio_de_gestao_2014.pdf

Prefeitura Municipal de Curitiba. (2015). Relatório de gestão 2015. Instituto Municipal de Administração Pública. Recuperado em 05 jan. 2019, de http://imap.curitiba.pr.gov.br/wp-content/uploads/2017/ 07/relatorio_de_gestao_2015.pdf

Prefeitura Municipal de Curitiba. (2016). Relatório de gestão 2016. Instituto Municipal de Administração Pública. Recuperado em 05 jan. 2019, de http://imap.curitiba.pr.gov.br/ wp-content/uploads/2017/07/RG_2016_completo.pdf

Prefeitura Municipal de Curitiba. (2017). Relatório de gestão 2017. Instituto Municipal de Administração Pública. Recuperado em 05 jan. 2019, de http://imap.curitiba.pr.gov.br/ wp-content/uploads/2018/02/RG2017_01_02_2018.pdf

Prefeitura Municipal de Curitiba. (2018). Relatório de gestão 2018. Instituto Municipal de Administração Pública. Recuperado em 05 jan. 2019, de http://imap.curitiba.pr.gov.br/wp-content/uploads/2019/ 02/0_RG_TOTAL_FINAL.pdf

Silva, E. F. d. (2018). Desafios da gestão por competências em Órgãos públicos. Conteúdo Jurídico. Recuperado em 24 fev. 2019, de https:// www.conteudojuridico.com.br/consulta/Artigos/46854/ desafios-da-gestao-por-competencias-em-orgaos-publicos
Como citar este artigo (APA):

Cubas, A. de F. P. (2018). Mapeamento do termo "conhecimento", segundo relatórios de gestão, no período de 2013 a 2018, na administração municipal de Curitiba. AtoZ: novas práticas em informação e conhecimento, 7(1), 12 - 20. Recuperado de: http:// dx.doi.org/10.5380/atoz.v7i1.65350 